\title{
17. DISSOLUTION AND PRESERVATION OF DIATOMS IN THE SEA OF JAPAN AND THE EFFECT ON SEDIMENT THANATOCOENOSIS ${ }^{\mid}$
}

\author{
Lloyd H. Burckle, ${ }^{2}$ Anne Sturz, ${ }^{3}$ and Guy Emanuele ${ }^{3}$
}

\begin{abstract}
Sediments of Pliocene age from the Sea of Japan as well as the North Pacific frequently contain abundant remains of the centric diatom, Coscinodiscus marginatus, a species which is neither abundant in surface waters nor in surface sediments of those regions. To test whether these occurrences are a product of opaline silica dissolution, we selected several sediment samples from the Quaternary record of Hole 798A which had opaline silica concentrations ranging from less than 5\% to approximately $16 \%$. Laboratory-timed dissolution experiments using an alkaline solution $\left(40 \mathrm{~mL}\right.$ of $2 \mathrm{M} \mathrm{Na}_{2} \mathrm{CO}_{3}$ ) were carried out at $80^{\circ} \mathrm{C}$ on the three bulk samples. At the end of each time interval the samples were centrifuged and the supernatant prepared for microscopic examination. The two samples with less than $5 \%$ opaline silica contained no diatoms or highly fragmented forms after the first 5 min of the experiment had elapsed. The third sample (with $16 \%$ opaline silica), however, showed an increase in percent $C$. marginatus as dissolution progressed (from less than $5 \%$ to more than $35 \%$ ). These data suggest that high abundances of $C$. marginatus in sediments may be due to silica dissolution rather than to any unique paleoceanographic signal.
\end{abstract}

\section{INTRODUCTION}

Several factors may compromise the utility of microfossils in timestratigraphic and paleoceanographic reconstructions. Over longer time scales, microfossil first and last occurrences may be diachronous, particularly between high and low latitudes and between major ocean basins. Burckle and Opdyke (1985), for example, pointed out that the last occurrence of the diatom, Actinocyclus ingens, is early late Miocene in the equatorial Pacific and latest Miocene in the North Pacific and that the first occurrence of the diatom, Neodenticula kamtschatica, ranges over an approximately million year interval in the North Pacific. In some cases, this diachrony may be considered trivial (i.e., although measurable, it falls within a zone or within the margin of error of biostratigraphic resolution) but it becomes non-trivial in light of the need to resolve time with greater resolution. Sorhannus et al. (1991), for example, noted that the first appearance of the diatom Rhizosolenia praebergonii in the Indian Ocean may be some 200 k.y. later than its first occurrence in the Pacific Ocean. Since this diachrony occurred during an interval of time which is now receiving some attention (early late Pliocene), it is important that it be recognized.

A second factor which may compromise the utility of microfossils, particularly diatoms, in paleoceanographic or paleoclimatic reconstructions is diagenesis, both post-depositional and within the water column. In considering diatoms in surface sediments Sancetta (1982), for example, noted that, in the absence of sediment trap data, a "predictive equation based on the relative abundance of species can yield incorrect values." Shemesh et al. (1989) showed that the sequence of dissolution of Antarctic diatoms in laboratory experiments is reflected in their spatial distribution in surface sediments of the Southern Ocean. The typical dissolution pattern in laboratory experiments of Antarctic diatom assemblages can be described by a decrease in percentage Nitzschia kerguelensis, an increase in percentage Thalassiosira lentiginosa, and a small increase in percentage Eucampia antarctica.

These data suggest that, in surface sediments, the $T$. lentiginosadominated assemblage is the product of dissolution and does not reflect the true diatom distribution in the overlying water masses. They concluded that "temperature transfer equations derived for the

${ }^{\prime}$ Pisciotto, K. A., Ingle, J. C., Jr., von Breymann, M. T., Barron, J., et al., 1992. Proc. ODP, Sci. Results, 127/128, Pt. 1: College Station, TX (Ocean Drilling Program).

2 Lamont-Doherty Geological Observatory, Palisades, NY 10964, U.S.A.

3 Scripps Institution of Oceanography, La Jolla, CA 92093, U.S.A.
Southern Ocean from surface sediment cannot be used safely without considering dissolution-induced changes upon diatom assemblages." That diatom dissolution may affect assemblages to the extent that their true paleoceanographic message is blurred is only now becoming apparent (largely because of the increase in sediment trap studies). One of us (LHB) is presently working on a middle/late Miocene site from the south Atlantic in which two different microfossil groups (diatoms and coccolithophorids) give contrasting temperature estimates; the coccolithophorids suggest a warm water environment while the diatom assemblage, which is dominated by one dissolution resistant species (Denticulopsis dimorpha), indicates a cold water environment. Such data suggests that the $D$. dimorpha-dominated assemblage is likely an artifact of dissolution and is giving a misleading paleoceanographic message.

This paper considers diatom dissolution in the Sea of Japan and the northwest Pacific, and its role in blurring or distorting the paleoceanographic record based on diatoms. On Leg 128 (Sea of Japan) thick diatomaceous sections of Pliocene age were encountered in which the diatom, Coscinodiscus marginatus, appeared to be a principle sedimentary component. In some samples, the relative abundance of this species exceeded $60 \%$. In the water column this species is found at mid-latitudes in all oceans although it can range into higher latitudes and is sometimes seen as a component, albeit minor, of low latitude upwelling systems. Coscinodiscus marginatus-rich assemblages have been described before in North Pacific and Sea of Japan Neogene sediments. Schrader (1973), for example, reported it from the eastern North Pacific and Koizumi (1973) reported it from the northwest Pacific. Burckle and Opdyke (1985) noted the presence of a $C$. marginatus-rich ooze ranging in age from late Miocene to Pliocene in a core from the north central Pacific. Specimens of $C$. marginatus showed visual evidence of dissolution before grading downward into an opal-poor interval around the middle of the late Miocene. In the Sea of Japan, Akiba (1982) reported the presence of an interval in the Pliocene with abundant C. marginatus and named it the C. marginatus zone. Similarly, he reported intervals of $C$. marginatus-rich sediments in continental marine sections from the west coast of Japan. Typically, such sediments were late Miocene to early Pliocene in age.

Kanaya and Koizumi (1966) reported that $C$. marginatus averages $10 \%-40 \%$ of the flora in subarctic surface sediment assemblages while Jouse (1962) noted that it is common, but not abundant, in the summer plankton of the central Sea of Okhotšk and that it has a similar distribution in underlying surface sediments. In the Sea of Japan, 
Tanimura (1981) reported that it does not exceed $10 \%$ in surface sediments while in our surface sediment data set (LHB) from this region it does not exceed $8 \%$ and is usually less than $4 \%$. Sancetta (1982) reviewed the taxonomy of this species as well as its spatial distribution in surface sediments of the North Pacific and concluded that it actually occurred in insignificant quantities, averaging less than $5 \%$ in Bering Sea basins and the North Pacific. She concluded that it usually occurred in higher abundances $(3 \%-5 \%)$ in winnowed areas (Aleutian Arc or Bowers Ridge) or in the Gulf of Alaska where silica dissolution has biased assemblages toward more resistant forms. Our unpublished data set from the North Pacific tends to bear out this conclusion. Previous work on both in situ and laboratory dissolution experiments on marine diatoms is given in Shemesh et al. (1989).

In quantitative paleoceanography the presence of high percentages of $C$. marginatus in pre-Holocene sediments would be considered a no-analog condition. High percentages of $C$. marginatus have not been observed in modern relatively undisturbed (i.e., undissolved) surface sediments. Therefore, no present-day analog exists which allows us to use high percentages of $C$. marginatus to characterize pre-Holocene water mass distribution. Here we investigate whether increases in percent $C$. marginatus in Sea of Japan sediments is the result of dissolution or whether it records a unique paleoceanographic event in the late Miocene and Pliocene. Our protocol largely follows that of Shemesh et al. (1989) with some deviations dictated by sediment type (Miocene/Pliocene sediments above the Opal A/Opal CT boundary tend to be diatom oozes while Quaternary sediments are largely silty clay to silty diatomaceous clay).

\section{MATERIALS AND METHODS}

Three bulk samples were obtained from Quaternary sediments in Hole 798A (12H-5, 100-101 cm; 14H-CC; and 15H-CC). Two samples had an opal content of less than $5 \%$ while the third had an opal content of approximately $16 \%$ (Dunbar et al., this volume); all showed at least traces of diatoms in smear slide examination. Where possible, i.e., where more than a trace of diatoms was present, the percent abundance of $C$. marginatus was determined (in fact, this was only true for the sample with $16 \%$ opaline silica). Since these samples were recovered from Quaternary sediment, percent abundance of $C$. marginatus was always low (i.e., $0 \%-5 \%$ ). In addition to the three bulk samples mentioned above we also took two samples from each section of the Quaternary and Pliocene parts of Holes 798A, 798B, and 799A. These samples were taken primarily for biostratigraphic and paleoenvironmental analysis, but the percent abundance of $C$. marginatus was also determined.

Laboratory-timed dissolution experiments using an alkaline solution were carried out at $80^{\circ} \mathrm{C}$ on the three Quaternary age bulk samples (Table 1). Five grams of each sample was macerated with mortar and pestle and dried at $65^{\circ} \mathrm{C}$ for $24 \mathrm{hr}$. For each timed interval of the experiment (5-60 min), a $20 \mathrm{mg}$ split was weighed into a centrifuge tube. The alkaline solution $\left(40 \mathrm{~mL}\right.$ of $\left.2 \mathrm{MNA}_{2} \mathrm{CO}_{3}\right)$ was introduced into the tubes at the experimental temperature and the tubes were placed in a thermostatic water bath $\left( \pm 1^{\circ} \mathrm{C}\right)$. At the end of each time interval the samples were centrifuged and the supernatants were saved in precleaned vials. The residual solids were washed with deionized water and saved for diatom enumeration. Permanent diatom

Table 1. Results of timed dissolution experiment.

\begin{tabular}{lccc}
\hline $\begin{array}{l}\text { Time } \\
(\mathrm{min})\end{array}$ & C. marginatus & Others & $\begin{array}{c}\text { C. marginatus } \\
(\%)\end{array}$ \\
\hline 0 & 13 & 290 & 4.29 \\
5 & 41 & 259 & 13.66 \\
15 & 44 & 256 & 14.66 \\
25 & 48 & 261 & 15.53 \\
35 & 126 & 195 & 39.25 \\
60 & 96 & 214 & 30.96 \\
\hline
\end{tabular}

slides of all samples (bulk samples as well as samples for biostratigraphic determinations) were made using methods described by Schrader (1974). A minimum of 300 diatoms were counted for each sample and placed in one of two categories (C. marginatus or others). Only those specimens with one half or more of the valve present were included in the count.

In order to apply observations of laboratory-induced dissolution patterns to naturally occurring sediment assemblages, it is desirable to show that the laboratory procedure mimics the natural process. In choosing a suitable laboratory protocol, we want one that is expedient and that speeds up the dissolution process, but does not otherwise change the treated sediments. For example, an experiment using seawater at temperatures on the order of $15^{\circ}-20^{\circ} \mathrm{C}$ closely represents the natural condition but would take a year or more to complete. We chose a more rapid procedure for our experiments: $\mathrm{Na}_{2} \mathrm{CO}_{3}$ at $80^{\circ} \mathrm{C}$. Though less representative of the natural condition, the experiments were completed within $4 \mathrm{hr}$ for each run.

Evidence supporting the assumption that the rapid dissolution procedure does not attack other components includes petrographic observation of untreated and treated sediments and chemical analysis of the leach fluid. Other than changes in diatom abundances, untreated and treated sediments appear identical when examined under the petrographic microscope. Dissolved aluminum in the leach solution, after sediment treatment, was less than $5 \mathrm{nM} \mathrm{Al}$. Very low concentrations of dissolved aluminum in the post-treatment fluid indicate that aluminosilicates, such as clay minerals, were not dissolved by the leach process. However, in spite of our presumption that the $80^{\circ} \mathrm{C}$ leach procedure dissolves only biogenic amorphous silica, the results of these experiments should be considered preliminary, pending development of a dissolution process that more closely mimics nature.

\section{RESULTS}

Shemesh et al. (1989) point out that the rate of opal dissolution is a function of dissolution temperature and the geologic age of the sample. They found that Holocene samples completely dissolved after $60 \mathrm{~min}$ at $85^{\circ} \mathrm{C}$ while at $240 \mathrm{~min}$ and $60^{\circ} \mathrm{C}$, only $80 \%$ had dissolved. The dissolution pattern of the three samples studied is a function of the original percent opaline silica content of the sample. In two samples with an opaline silica content of less than $5 \%$, and with only traces of diatoms in smear slide examination, no diatoms were present after $60 \mathrm{~min}$. Indeed, the sample was essentially barren of diatoms after the first $10 \mathrm{~min}$ of dissolution. Sample $798 \mathrm{~A}-12 \mathrm{H}, 100-101 \mathrm{~cm}$, differed, however, in that, in smear slide examination of the untreated sediment, common to abundant diatoms were observed, opal content exceeded $15 \%$ and the diatom count on the undissolved sample showed a percent abundance of C. marginatus of slightly less than $5 \%$.

Results of the dissolution of this sample are shown in Figure 1. Its dissolution pattern is characterized by an increase in relative abundance of $C$. marginatus and a drop in relative abundance of fragile, weakly silicified forms in the first $10 \mathrm{~min}$ (consisting largely of Coscinodiscus spp.). Accompanying this increase in C. marginatus is a modest increase in broken valve fragments of the genus Thalassionema. This genus, as well as Thalassiothrix spp. appears to have a variable response to laboratory and in situ dissolution, sometimes being high-graded by this process and, at other times, decreasing in relative abundance (Shemesh et al., 1989). Much of the increase in relative abundance of $C$. marginatus takes place in the latter stages of dissolution; after $35 \mathrm{~min}$ the relative abundance of $C$. marginatus rises to approximately $40 \%$ but drops to less than $35 \%$ at the end of the experiment $(60 \mathrm{~min})$. These numbers are within the margin of error of our counts and suggest that very little dissolution took place after $35 \mathrm{~min}$ to the end of the run $(60 \mathrm{~min})$.

Figures 2 and 3 show the results of the relative abundance count of C. marginatus in Holes 798A and B and 799A. To further resolve the chronostratigraphy we also included the magnetostratigraphy and biostratigraphy (i.e., diatom datum levels; Burckle, this volume). 


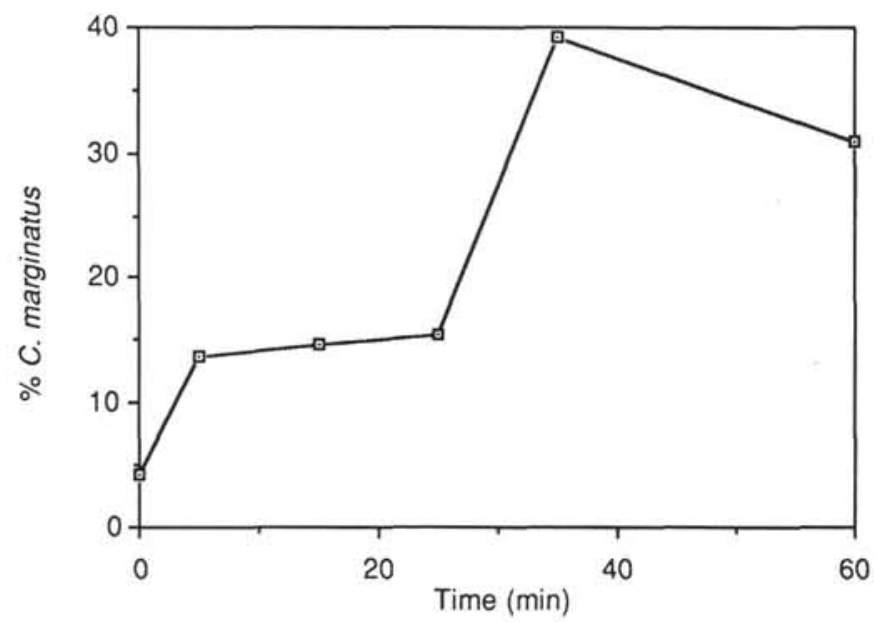

Figure 1. Results of timed dissolution of $C$. marginatus. Percent is based upon a count of 300 specimens.

These datum levels have previously been tied to the magnetostratigraphy in deep sea sediments of the northwest Pacific (Koizumi and Tanimura, 1985); the Last Appearance Datum (LAD) of Rhizosolenia curvirostris has also been tied to the oxygen isotope record in the north Pacific at an age of $276 \mathrm{k}$.y. (Morley et al., 1982). We have made the unsubstantiated assumption that the diatom LAD levels in the northwest Pacific and the Sea of Japan are time-correlative.

Although percent abundance of this species is similar during the middle and late Quaternary of both Site 798 and 799 (usually less than $5 \%$ ), it differs slightly between the two sites in the earliest Pleistocene. At Site 798 (the slightly more southerly site) percent $C$. marginatus increases to $6 \%-8 \%$ during the early Pleistocene before increasing to as much as $12 \%$ in the late Pliocene. Figure 2 shows that this increase is maintained down into the Gauss magnetic chron. Although percent determinations were not made in the lower part of Site 798, smear slide analysis indicates that percent $C$. marginatus also tends to be high in this interval (i.e., above the Opal A/Opal CT boundary). Site 799 has a somewhat different pattern in percent $C$. marginatus. Figure 3 shows that while percent abundance of this species increases to near $10 \%$ in the latest Pliocene, the major increase (to more than $30 \%$ ) occurs earlier just below the Gauss/Matuyama magnetic chron boundary at about 2.5 Ma). Further downsection percent abundance increases to, at times, over $60 \%$ and increased relative abundance of this species persists down to the opal A/opal CT transition (approximately $450 \mathrm{~m}$; Fig. 3).

As noted above, late Neogene increases in relative abundance of C. marginatus have long been recognized in North Pacific and Sea of Japan sediments. Figure 4 shows late Neogene abundance of this species in core $\mathrm{RC} 12-431\left(43^{\circ} 38^{\prime} \mathrm{N}, 167^{\circ} 49^{\prime} \mathrm{W}\right)$ plotted against the paleomagnetic stratigraphy (data redrawn from Burckle and Opdyke, 1986). Although relative abundance counts were not made, C. marginatus so dominated the assemblage that, near the lower part of its range, there were few other floral elements; near the transition to a barren sediment, valves of this species showed evidence of severe dissolution. The uppermost limit of high abundance could not be determined because of numerous unconformities near the core top, but stratigraphic evidence suggests that it occurred in the Pliocene, quite probably the upper Pliocene.

Coscinodiscus marginatus abundances in two DSDP sites from the North Pacific (DSDP Sites 438 and 581, Fig. 5) are also considered (Koizumi, 1985). Site $581\left(43^{\circ} 55.62^{\prime} \mathrm{N}, 159^{\circ} 47.76^{\prime} \mathrm{E}\right)$ has a single peak of $C$. marginatus in the upper Miocene and another in the lower Pliocene. Site $438\left(40^{\circ} 37.8^{\prime} \mathrm{N}, 143^{\circ} 14.8^{\prime} \mathrm{E}\right)$, on the other hand, has a number of peaks in the upper Miocene; there are no data for the Pliocene. Both sites indicate low relative abundance of this species in the middle Miocene. Unlike core RC12-431, neither one of these has a diatom barren zone underlying the oldest $C$. marginatus peak. In contrast to most of the sections described above, continental marine sections from the Noto Peninsula (western Honshu Island) bordering the Sea of Japan, show a $C$. marginatus peak straddling the middle/upper Miocene boundary and relatively low values for the upper Miocene through Pleistocene (Fig. 6; Koizumi, 1968)

\section{DISCUSSION}

It is generally considered that percent opal in sediment is a measure of past relative surface water productivity. Mortlock et al. (1991), for example, have shown that opal percent is high in the Southern Ocean during interglacials and low during glacial episodes reflecting the inhibiting effect that increased sea ice distribution has upon surface water productivity. Burckle et al (1990) also pointed out that, in sediment cores taken closer to the Antarctic continent, changes in sea ice distribution appear to dictate productivity and, thus, changes in opal percent. In the Sea of Japan, increased opal content (and increased concentrations of diatoms and radiolarians) occurs during interglacials while low percent opal occurs during glacials (Dunbar et al., this volume; LHB, unpubl. notes). This is likely due to the fact that transport of Tsushima Current water into the Sea of Japan (via the Tsushima Strait) during glacials is considerably restricted (Morley and Heusser, 1989). In our unpublished data set (Burckle, unpubl. data) from a radiocarbon dated deep sea core ( $\mathrm{RC12}-379)$ taken from the southeastern part of the Sea of Japan, both diatom and radiolarian abundances show low values during the Last Glacial Maximum and increase during the Holocene.

In our laboratory experiments to produce a $C$. marginatus ooze via timed dissolution, two basic observations are apparent. Such an ooze will not result if the original opal content is below $5 \%$ even when diatoms, and especially $C$. marginatus, are present in smear slide examination. On the other hand, when the opal percent is high (say, on the order of $15 \%-20 \%)$ C. marginatus is high-graded and will become one of the dominant components. We conclude from this that a $C$. marginatus ooze, even though it is a remnant of a dissolved assemblage, represents high productivity, although such an assemblage does not reflect the true temperature/salinity regime that existed in surface waters at the time of deposition.

In the two Sea of Japan ODP sites studied by us, $C$. marginatus abundance is high in the Pliocene (although the amplitude is greater in Site 799 than Site 798) but drops to near Quaternary abundance levels in the late Pliocene around the Gauss/Matuyama boundary. In both sites there is a modest abundance peak in the lowermost Matuyama while the Quaternary is characterized by abundance levels of $0 \%$ to less than $5 \%$ (indeed, frequently there were too few diatoms to be counted). In both the Sea of Japan and the northwest Pacific, glacial intervals are characterized by low biosiliceous productivity while interglacials are characterized by high productivity (Robertson, 1975; Morley and Dworetzky, 1991). These latter authors also noted that during the Pliocene, prior to about $2.5 \mathrm{Ma}$, the northern subtropical and subpolar Pacific experienced climate conditions warmer than those of today. We suggest that the undissolved remnant of the higher productivity associated with these warmer (but not tropical or subtropical) waters is the $C$. marginatus-rich sediment preserved in Miocene/Pliocene sediments of the North Pacific and the Sea of Japan (higher surface water productivity is also demonstrated in the percent opal data which shows highest average values as well as higher opal accumulation rates in the Pliocene; Dunbar et al., this volume).

The suggestion relating a $C$. marginatus-rich sediment to increased productivity in a warmer water environment is supported, in part at least, by the conclusion of Morley and Dworetzky (1991). These authors noted that, compared with the late Pleistocene, biosiliceous productivity (i.e., numbers of radiolarians per gram of sediment) was higher during the late Pliocene and early Pleistocene in DSDP Sites 579 and 580 (northwest Pacific), with late Pliocene values generally higher than those determined for the early Pleistocene. Indeed, the $C$. marginatus abundance 


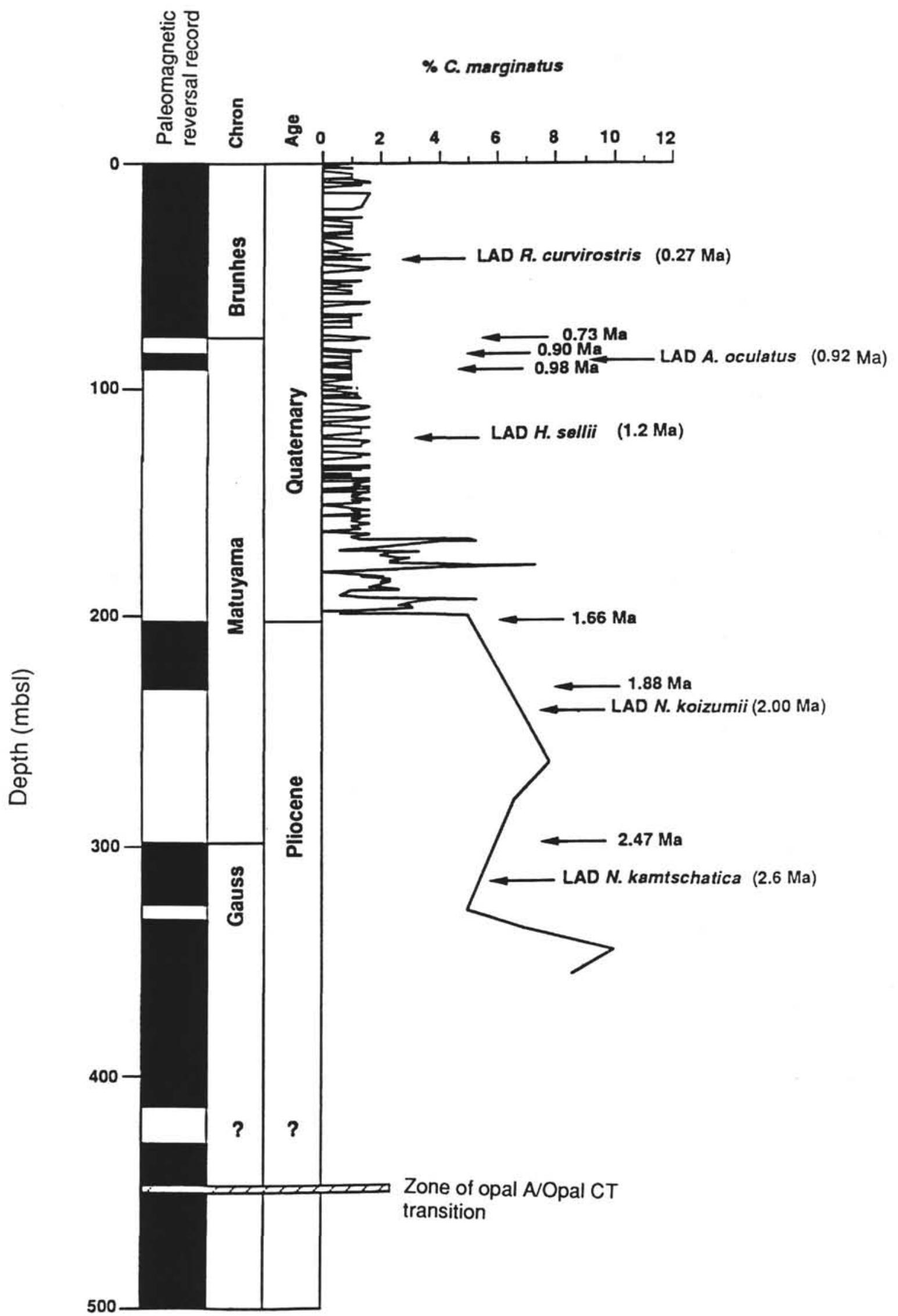

Figure 2. Percent abundance of $C$. marginatus for Hole 798A. Because of dissolution we are unsure of age control toward bottom of hole. 
record on these two sites (Burckle, unpubl. data) closely parallels the results of Morley and Dworetzky (1991); i.e., relative abundance of C. marginatus increases in intervals of increased biosiliceous productivity. Implicit in this conclusion is the realization that highest productivity in the Sea of Japan occurred at a time when the southern gateway to the Sea of Japan (the Tsushima Strait) was closed. In data sets recovered by Leg 128 micropaleontologists, it was obvious that warm water microfossils first appeared in Sea of Japan sediments around the Pliocene/Pleistocene boundary; prior to that time this strait was closed and there was a more northerly gateway into the sea.

Although we conclude that $C$. marginatus-rich sediment in the Sea of Japan and the north Pacific represents higher relative productivity and is an artifact of dissolution, we cannot discern the agents of dissolution. The fact that such sediment persists down to the opal A/opal CT boundary suggests to us that dissolution may be related to the upward migration of this boundary. Similarly, the presence of a silica barren zone below a C. marginatus ooze in core RC12-431 and the fact that, in that core, individual diatom valves show increased dissolution toward the base of that ooze suggests a genetic relationship between the two.

\section{ACKNOWLEDGMENTS}

Discussions with colleagues on board Leg 128 were most helpful and are appreciated. This research was supported by a JOI/USSAC grant to LHB and AS.

\section{REFERENCES}

Akiba, F., 1982. Reconsideration of the Coscinodiscus marginatus zonetaxonomy and biostratigraphic significance of Thalassiosira schraderi. Bull. Tech. Lab. JAPEX, 24:206-223.

Burckle, L. H., Gersonde, R., and Abrams, N., 1990. Late Pliocene-Pleistocene paleoclimate in the Jane Basin regions: ODP Site 697. In Barker, P. F., Kennett, JP., et al., Proc. ODP, Sci. Results, 113: College Station, TX (Ocean Drilling Program), 803-809.

Burckle, L. H., and Opdyke, N. D., 1985. Latest Miocene/earliest Pliocene diatom correlation in the north Pacific. Mem.-Geol. Soc. Am., 163:37-48.

Jouse, A. P., 1962. Stratigraphic and paleogeographic investigations in the northwest part of the Pacific ocean. Akad. Nauk SSR Oceanol. Inst., Moscow. (in Russian)

Kanaya, T., and Koizumi, I., 1966. Interpretation of diatom thanatocoenosis from the north Pacific applied to a study of core V20-130. Sci. Rep. Tohoku Univ. Ser. 2, 37:89-130.
Koizumi, I., 1968. Tertiary diatom flora of Oga Peninsula, Akita Prefecture, northeast Japan. Sci. Rep. Tohuku Univ. Ser. 2, 40:171.

, 1973. The late Cenozoic diatoms of sites 183-192, Leg 19, Deep Sea Drilling Project. In Creager, J. S., Scholl, D. W., et al., Init. Repts. DSDP, 19: Washington (U.S. Govt. Printing Office), 805-855.

Koizumi, I., and Tanimura, Y., 1985. Neogene diatom biostratigraphy of the middle latitude western North Pacific, Deep Sea Drilling Project Leg 86. In Heath, G. R., Burckle, L. H., et al., Init. Repts. DSDP, 86: Washington (U.S. Govt. Printing Office), 269-300.

Morley, J. J., and Dworetzky, B., 1991. Evolving Pliocene-Pleistocene climate: a north Pacific perspective. Quat. Sci. Rev., 10:225-238.

Morley, J. J., Hays, J. D., and Robertson, J. H., 1982. Stratigraphic framework for the late Pleistocene in the northwest Pacific ocean. Deep-Sea Res. Part A. 29:1485-1499.

Morley, J. J., and Heusser, L., 1989. Late Quaternary atmospheric and oceanographic variations in the western Pacific inferred from pollen and radiolarian analyses. Quat. Sci. Rev., 8:263-276.

Mortlock, R. A., Charles, C. D., Zibello, M. E., Froelich, P. N., Hays, J. D., and Burckle, L., 1991. Testing the polar nutrient hypothesis: the biogenic silica record in the Antarctic. Nature, 351:220-223.

Robertson, J., 1975. Glacial to interglacial oceanographic changes in the northwest Pacific, including a continuous record of the last 140,000 years [Ph.D. dissert.]. Columbia Univ., New York.

Sancetta, C., 1982. Distribution of diatom species in surface sediments of the Bering and Okhotsk seas. Micropaleontology, 28:1-6.

Schrader, H.-J., 1973. Cenozoic diatoms from the northeastern Pacific, Leg 18. In Kulm, L. D., von Huene, R., et al., Init. Repts. DSDP, 18: Washington (U.S. Govt. Printing Office), 673-797.

, 1974. Proposal for a standardized method of cleaning diatom-bearing deep-sea and land-exposed marine sediments. Nova Hedwegia Beih., 45:403-409.

Shemesh, A., Burckle, L. H., and Froelich, P. N., 1989. Dissolution and preservation of antarctic diatoms and the effect on sediment thanatocoenoses. Quat. Res., 31:288-308.

Sorhannus, U., Fenster, E., Hoffman, A., Burckle, L. H., 1991. Iterative evolution in the diatom genus Rhizosolenia. Lethaia, 24:39-44.

Tanimura, Y., 1981. Late Quaternary diatoms of the Sea of Japan. Sci. Rep. Tohoku Univ. Ser. 2, 51:1-36.

Date of initial receipt: 17 April 1991

Date of acceptance: 4 February 1991

Ms 127/128B-137 
Hole 799A

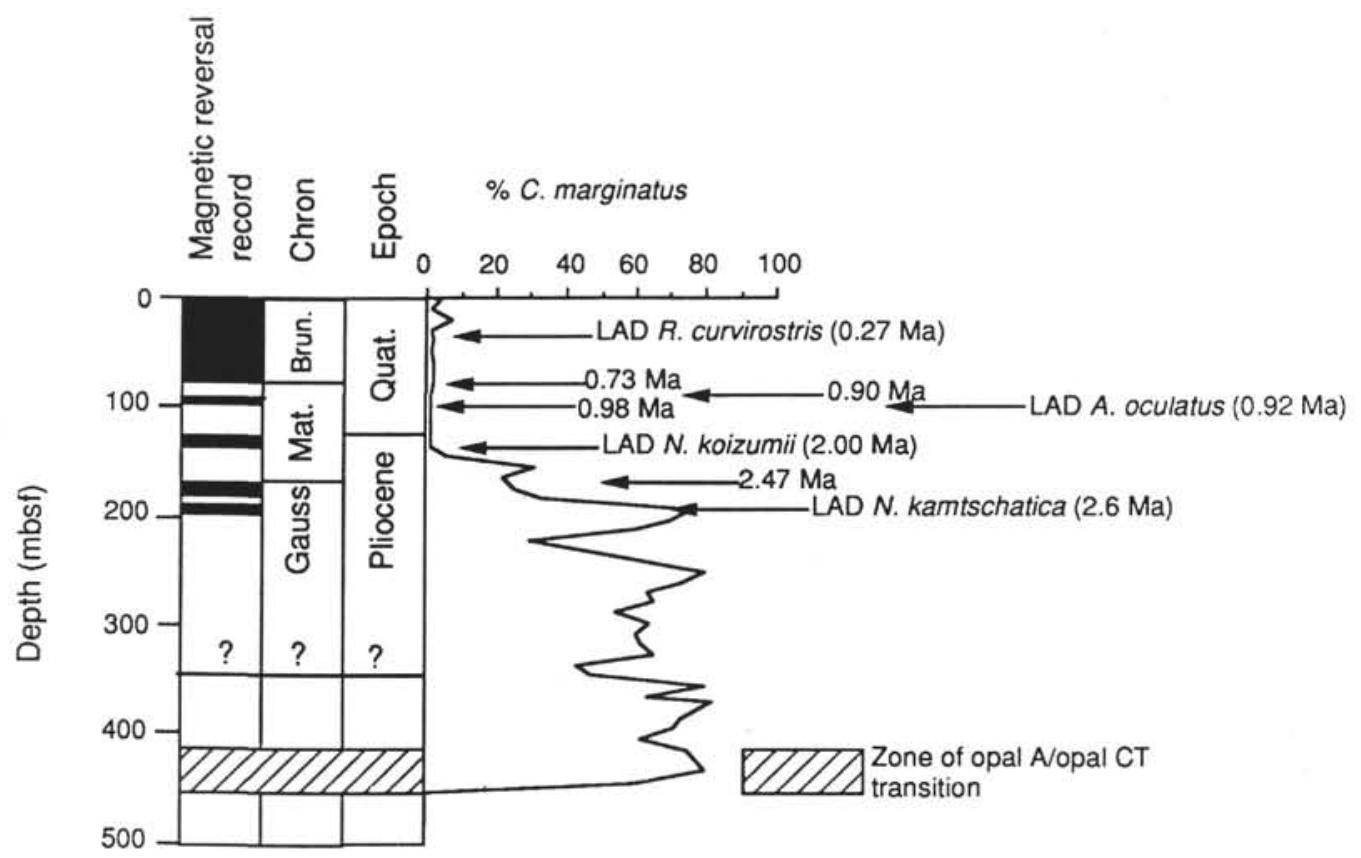

Figure 3. Percent abundance of $C$. marginatus for Hole 799A. Because of dissolution we are unsure of age control toward bottom of hole. 

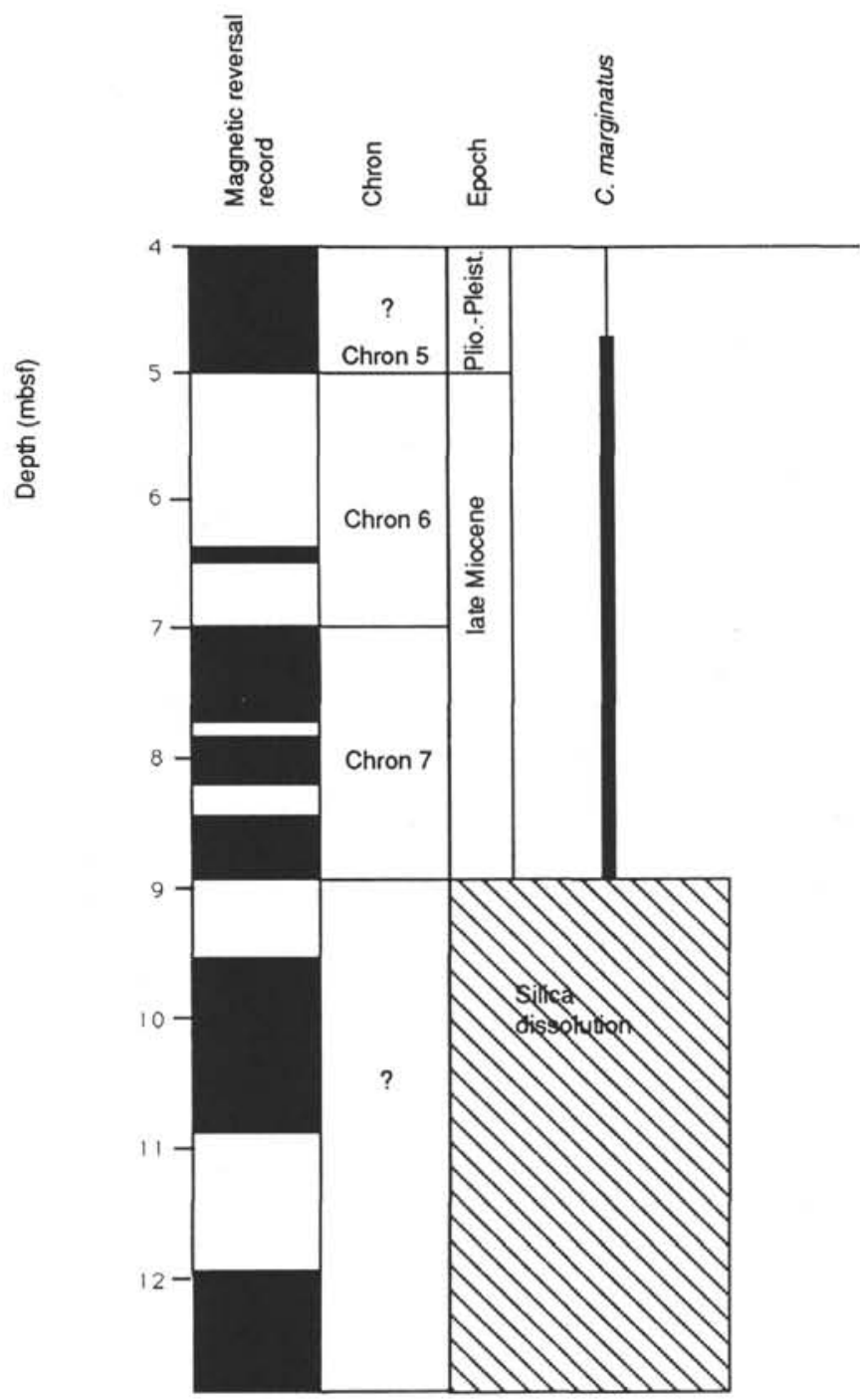

Figure 4. Relative abundance of $C$. marginatus in upper Miocene/Pliocene sediments of core RC12-431 from the North Pacific. 
$\%$ C. marginatus

Site 581

Site 433
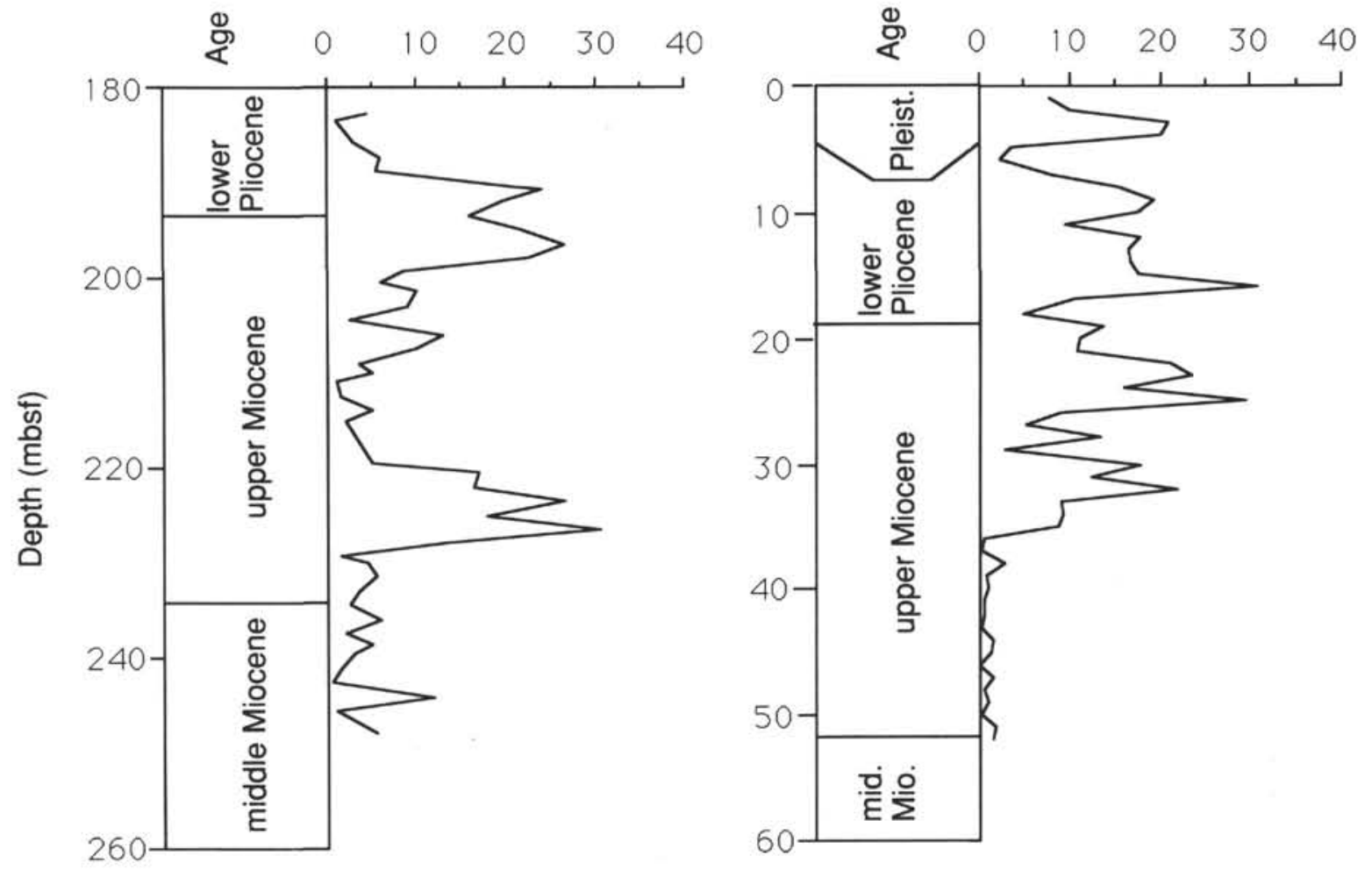

Figure 5. Percent abundance of $C$. marginatus in two DSDP sites from the North Pacific. Data from Site 581 are taken from Koizumi and Tanimura (1985); Site 433 data from Koizumi (1980).

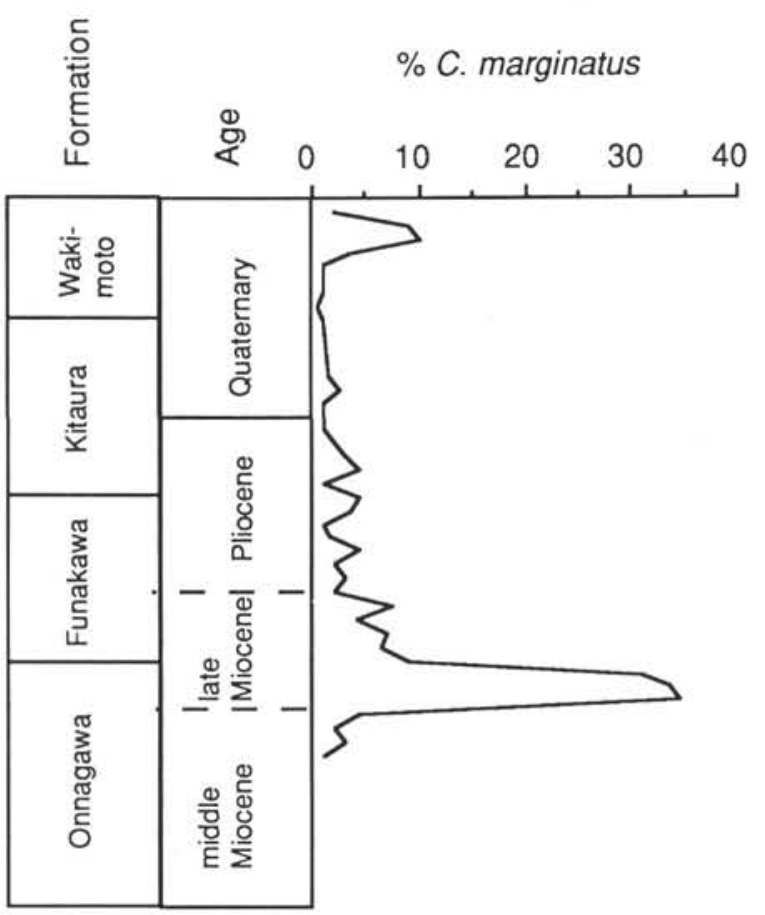

Figure 6. Percent abundance of C. marginatus from the Aikawa section, western Honshu, Japan. Data are taken from Koizumi (1968). 